\title{
MODEL KONSERVASI SUMBERDAYA AIR SEBAGAI UPAYA MEMPERTAHANKAN KEBERLANJUTAN AIR DI SUB DAS AEK SILANG
}

\author{
Irwan Valentinus Sihotang ${ }^{1}$, Sudarmadji2, Ig.L.Setyawan Purnama², \\ M. Baiquni² \\ 1 Mahasiswa Program Doktor Ilmu Lingkungan, Fakultas Pasca Sarjana UGM, \\ 2 Dosen Fakultas Geografi UGM \\ E-mail: irwanvalen.sihotang@gmail.com.
}

\begin{abstract}
Continuous availability of water as a basic requirement for survival and for the purposes of production so need to be maintained. The availability of water resources is strongly influenced by environmental and natural resource management is done by humans. Water resource conservation efforts through the increased role of the parties is expected sustainability of water can be maintained. The research objective is to formulate a model of conservation of water resources and efforts needed for water sustainability can be maintained. Data were collected using questionnaires and interviews, and then analyzed descriptively by using a technique AHP (Analytical Hierarchy Process).

The results of the analysis with AHP technique showed that the main priority of the alternative strategy of water resources conservation activities is to preserve water (38.70\%). The effort to preserve water is technically civilian conservation, forest and land rehabilitation $(R H L)$, control the use of water, maintenance of water resources and coaching/mentoring for communitie.
\end{abstract}

\section{Keywords: Sustainable water, Water resource conservation, AHP, Preserve water}

\section{PENDAHULUAN}

Salah satu sumber daya alam yang memiliki peranan penting bagi sumber kehidupan bagi manusia dan mahluk hidup lainnya adalah air. Pengelolaan sumber daya alam dan lingkungan tentunya akan mempengaruhi ketersediaan air. Pengelolaan sumber daya alam dan lingkungan saat ini dan masa mendatang akan menghadapi tantangan yang sulit, karena terjadinya perubahan iklim global, aktivitas ma nusia terhadap pemanfaatan lahan yang mengakibatkan perubahan fungsi lahan Perubahan tutupan lahan memiliki hubungan yang erat terhadap perubahan iklim terutama curah hujan (Igbawua, dkk., 2016 ; Zeppel, dkk.,2014 ; Asner, dkk., 2010; Asdak, 2010).

Pengubahan bentang alam, bentuk lahan dan pemanfaatan lahan akan mempengaruhi sistem hidrologi, hal ini berkaitan dengan besar-kecilnya aliran permukaan (runoff), sebaran, jumlah dan kualitas air, cadangan, pemasukan ke tanah dan limpasan. Air hujan ada yang langsung mengalir di atas permukaan tanah dan ada yang meresap ke dalam tanah, dimana pada tingkat kelembaban tertentu air tersebut akan keluar lagi ke permukaan tanah (subsurface flow) dan ada yang langsung mengalir ke sungai sebagai base flow (Ongkosongo, 2010; Liu, 2005). Pengubahan bentang alam, bentuk lahan dan pemanfaatan lahan biasanya diakibatkan oleh aktivitas manusia.

Hubungan antara aktivitas manusia dengan kondisi sumberdaya alam terutama air sangat erat (Irawan, dkk., 2014; Muta'ali, 2012; Liu dan Yaning, 2006; Gilbert, 2005). Laju pertumbuhan penduduk akan menyebabkan kebutuhan sumberdaya air semakin meningkat, pola 
pemanfaatan lahan terutama untuk persawahan sangat membutuhkan air, aktivitas perubahan tanaman hutan menjadi tanaman pertanian yang menyebabkan kemampuan tanah untuk menyimpan air semakin berkurang (Indra, 2013; Rachmat, 2007; Sihite, 2005).

Danau Toba sebagai danau terbesar di Indonesia ( $\pm 116.002,06$ ha), memiliki sumber daya air yang dimanfaatkan untuk berbagai sektor. Hal ini menggambarkan bahwa ketersediaan air Danau Toba memegang peranan penting baik bagi kelangsungan kehidupan, juga bagi kemajuan perekonomian daerah di Sumatera Utara. Salah satu Sub DAS yang masih berfungsi sebagai penyumbang air secara permanen (sepanjang tahun) ke Danau Toba adalah Sub DAS Aek Silang (Loebis, 1999). Sub DAS Aek Silang memiliki luas 19.814,72 ha juga memiliki nilai strategis, karena air dari sungai tersebut dimanfaatkan untuk industri Pembangkit Listrik Tenaga Mikro Hidro (PLTMH) dengan kapasitas produksi listrik sebesar $750 \mathrm{KWh}$.

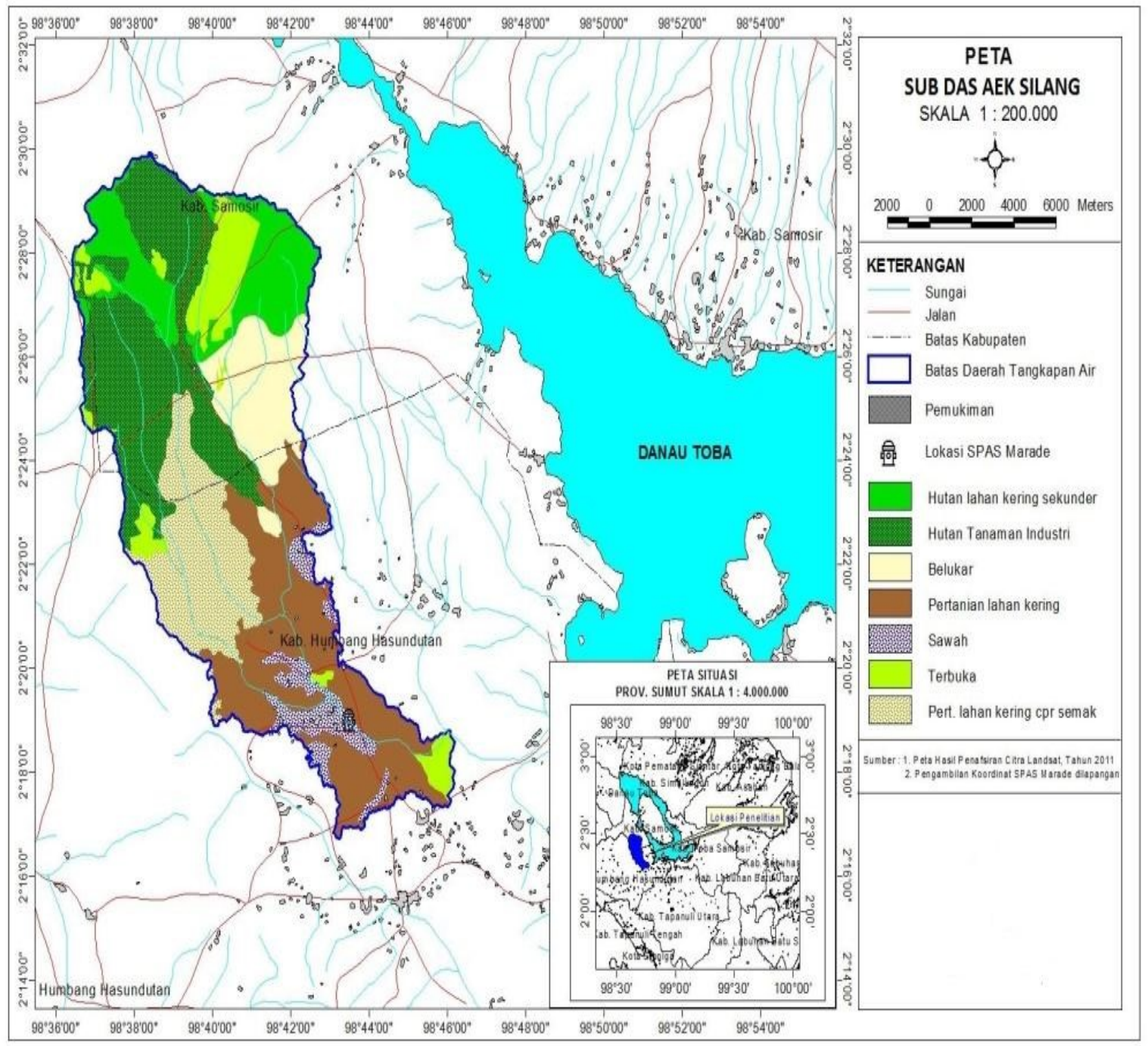

Gambar 1: Peta Sub DAS Aek Silang 
Upaya untuk mempertahankan keberlanjutan adalah melalui kegiatan konservasi sumberdaya air (Sudarmadji,dkk., 2012; Marganingrum, 2007; Arsyad, 2006). Menurut Kodoatie dan Roestam (2010), kegiatan konservasi sumberdaya air terdiri dari 3 (tiga) kegiatan pokok, yaitu 1) perlindungan dan pelestarian sumberdaya air; 2) pengawetan air dan 3) pengelolaan kualitas air dan pengendalian pencemaran air. Dukungan dan peran partisipasi dari berbagai pihak baik, pemerintah, dunia usaha, lembaga perguruan tinggi dan kelompok masyarakat sangat dibutuhkan dalam menjaga kelestarian sumberdaya air melalui kegiatan konservasi (Sudarmadji,dkk.,2012; Jonsson, 2005).

Penelitian ini bertujuan untuk merumuskan model konservasi sumberdaya air dan upaya-upaya yang dibutuhkan agar keberlanjutan air di Sub DAS Aek Silang dapat dipertahankan.

\section{METODOLOGI PENELITIAN}

Ketersediaan air dari waktu ke waktu akan menjadi permasalahan ketika kebutuhan air terus meningkat, sedangkan penyediaan air tetap dan cenderung menurun karena kemampuan alam menahan air semakin berkurang. Upaya untuk menjaga kesinambungan ketersediaan air adalah melalui kegiatan konservasi sumberdaya air. Kegiatan konservasi sumber daya air terdiri dari 3 (tiga) pokok kegiatan utama, yaitu perlindungan dan pelestarian sumberdaya air, pengawetan air dan pengelolaan kualitas air serta pengendalian pencemaran air. Pemilihan atau penentuan model kegiatan konservasi sumber daya air adalah dengan menggunakan metode Analytical Hierarchy Process (AHP).

Para pihak yang dipilih adalah yang memahami kondisi Sub DAS Silang dan memiliki pengetahuan terhadap kegiatan konservasi sumberdaya air, seperti intansi pemerintah, dunia usaha, perguruan tinggi, lembaga swadaya masyarakat (LSM) dan masyarakat petani. Sasaran manusia yang menjadi input utama dalam penelitian adalah terdiri dari kelompok Pemerintah (pemerintah pusat dan pemerintah daerah), kelompok dunia usaha, kelompok perguruan tinggi dan kelompok masyarakat. Peran dari masingmasing kelompok tersebut terhadap ketersediaan air adalah sebagai berikut :

a. Kelompok Pemerintah adalah kelompok yang memiliki kewenangan pembuat kebijakan pembangunan yang berkaitan dengan ketersediaan air.

b. Kelompok Dunia Usaha adalah sebagai kelompok yang menfaatkan dan mempengaruhi ketersediaan air.

c. Kelompok Perguruan Tinggi adalah sebagai kelompok yang memiliki ilmu pengetahuan dan teknologi dalam menjaga ketersediaan air.

d. Kelompok Masyarakat (LSM dan masyarakat petani) adalah sebagai kelompok yang memanfaatkan ketersediaan air, memantau pembangunan yang berkaitan dengan ketersediaan air dan mempengaruhi ketersediaan air.

Kerangka pemikiran penelitian seperti terlihat pada gambar berikut. 


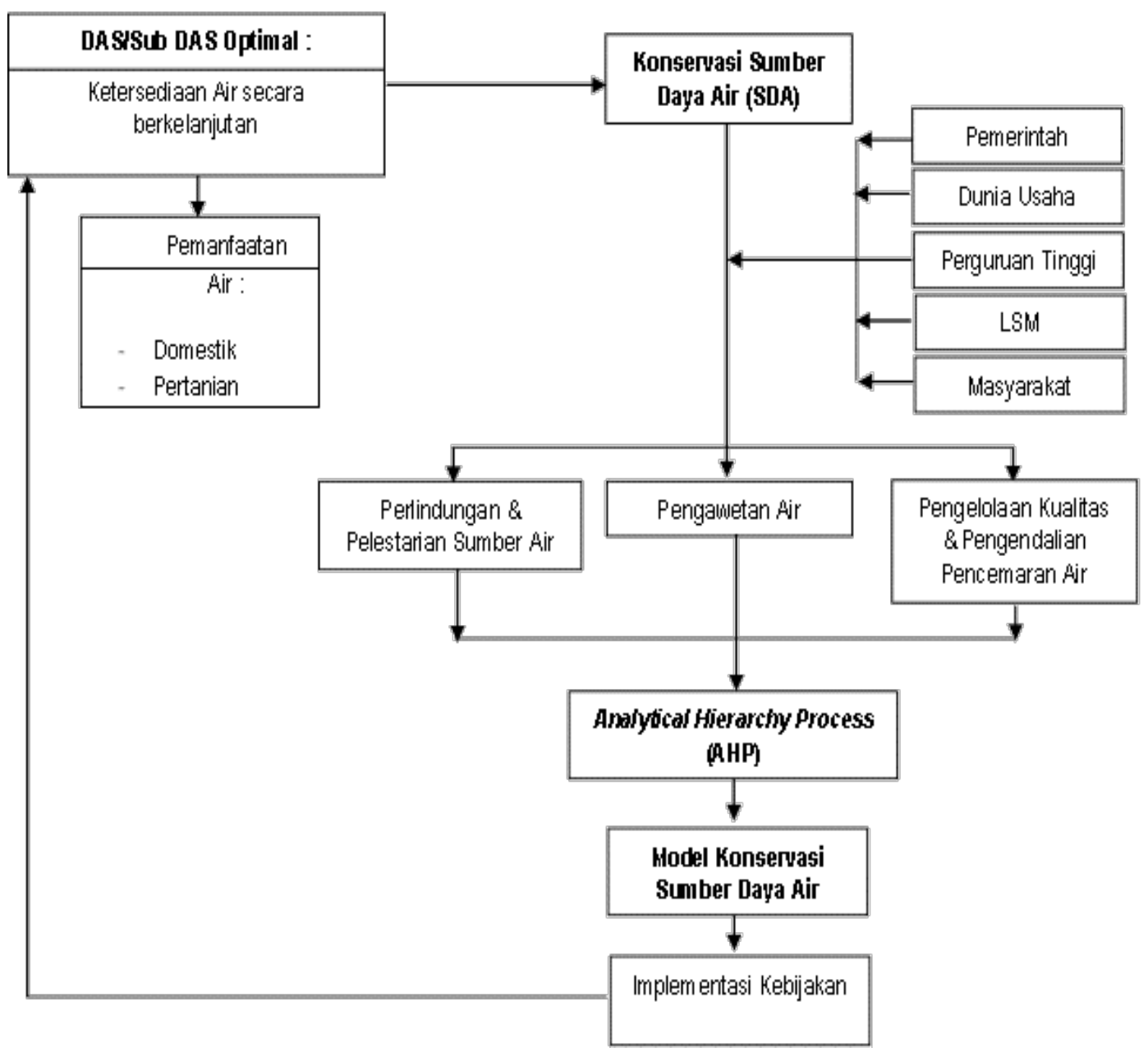

Gambar 2. Kerangka Pemikiran Strategi Konservasi Sumberdaya Air dengan Menggunakan Model AHP

Penelitian dilaksanakan selama empat bulan sejak Juli 2014 hingga Oktober 2014. Lokasi penelitian adalah di Sub DAS Aek Silang, DTA Danau Toba, Propinsi Sumatera Utara. Secara geografis Sub DAS Aek Silang terletak pada koordinat 02015'00" LU sampai dengan 02030'00" LU dan 98036'00" BT sampai dengan 98056'00" BT. Disamping itu Sub DAS Aek Silang berada di 2 (dua) kabupaten yaitu Kabupaten Humbang Hasundutan (Humbahas) dan Kabupaten Samosir.

Jenis data yang dikumpulkan ada 2 (dua) jenis yaitu data primer dan data sekunder. Pengumpulan data primer dilakukan melalui wawancara mendalam terhadap para pihak (Pemerintah, Dunia Usaha, LSM, Perguruan Tinggi dan Masyarakat) yang terkait dengan konservasi sumber daya air. Sedangkan pengumpulan data sekunder berupa data iklim (curah hujan), data debit sungai dan data kependudukan yang diperoleh dari berbagai instansi seperti BMKG, Balai Wilayah Sungai dan BPS.

Prosedur penelitian dan pengumpulan data meliputi :

1. Pengamatan lapangan kondisi ketersediaan air di Sub DAS Aek Silang. 
2. Pengisian kuisioner yang dibuat berdasarkan kaidah AHP, dimana pertanyaannya secara keseluruhaan terkait dengan kegiatan konservasi sumberdaya air (SDA).

3. Wawancara secara mendalam dengan para pihak terpilih yang dianggap mengetahui dan memahami kegiatan konservasi SDA yang dibutuhkan untuk mempertahankan keberlanjutan air di Sub DAS Aek Silang. Jumlah responden masing-masing kelompok dapat dilihat pada Tabel 1.

Tabel 1. Jumlah Responden Masing-masing Kelompok

\begin{tabular}{|c|c|c|}
\hline No. & Kelompok Responden & Jumlah Responden (Orang) \\
\hline \multirow[t]{5}{*}{1.} & Pemerintah & \\
\hline & - Pemerintah Pusat & 2 \\
\hline & - $\quad$ Pemerintah Propinsi & 3 \\
\hline & - $\quad$ Pemerintah Kab.Humbahas & 6 \\
\hline & - $\quad$ Pemerintah Kab. Samosir & 6 \\
\hline \multirow[t]{3}{*}{2.} & Dunia usaha & \\
\hline & - PT. PLN & 1 \\
\hline & - $\quad$ PT. TPL & 1 \\
\hline 3. & Perguruan Tinggi & 4 \\
\hline \multirow[t]{3}{*}{4.} & Masyarakat: & \\
\hline & - Masyarakat Desa & 100 \\
\hline & - $\quad$ Forum DAS Asahan Toba (LSM) & 2 \\
\hline & Jumlah Responden & 125 \\
\hline
\end{tabular}

Sistem Analytical Hierarchy Process (AHP) yang dikembangkan oleh Thomas L. Saaty adalah sebuah pendekatan pengambilan keputusan yang dirancang untuk membantu menyelesaikan problematika dengan kriteria yang sangat kompleks dengan cara menghimpun persepsi orang yang berhubungan sangat erat dengan permasalahan tertentu secara rasional melalui suatu prosedur untuk sampai pada suatu skala preferensi dari berbagai alternatif (Ethika, dkk., 2014; Park, 2010; Kim, dkk.,2009). Metode AHP, menghasilkan alternatif keputusan terbaik yang berdasarkan penetapan prioritas kebijakan berdasarkan rasional persepsi orang.

Pengambilan keputusan yang prioritas dengan menggunakan AHP adalah memerlukan penguraian keputusan dengan beberapa tahapan (Saaty, 2008), sebagai berikut:
a. Identifikasi
permasalahan
masalah.
Adapun
dalam penelitian ini

adalah bagaimana model kegiatan konservasi sumber daya air yang dibutuhkan untuk mempertahankan keberlanjutan air di Sub DAS Aek Silang agar tetap berkelanjutan.

b. Menyusun hirarki prioritas keputusan, sebagai berikut : level pertama adalah fokus, level kedua adalah faktor-faktor yang mempengaruhi, level ketiga adalah aktor yang berperan, level keempat adalah tujuan yang hendak dicapai dan level kelima adalah alternatif kebijakan/keputusan/strategi.

c. Penentuan tingkat kepentingan pada setiap hirarki dengan menggunakan matriks komparasi berpasangan. Matriks komparasi berpasangan dengan cara membandingkan elemen yang satu dengan elemen lainnya dalam satu level secara berpasangan sehingga diperoleh nilai kepentingan dari masing-masing elemen (diperoleh dari hasil wawancara langsung dengan responden) 
Tabel 2.: Skala Perbandingan secara Berpasangan

\begin{tabular}{cll}
$\begin{array}{c}\text { Intensitas } \\
\text { Kepentingan }\end{array}$ & \multicolumn{1}{c}{ Keterangan } & Penjelasan \\
\hline 1 & Kedua elemen sama pentingnya & $\begin{array}{l}\text { Dua elemen mempunyai pengaruh yang sama besarnya } \\
\text { terhadap tujuan }\end{array}$ \\
\hline 3 & $\begin{array}{l}\text { Elemen yang satu sedikit lebih penting daripada } \\
\text { elemen lainnya }\end{array}$ & $\begin{array}{l}\text { Pengalaman dan penilaian sedikit menyokong satu elemen } \\
\text { dibandingkan elemen lainnya }\end{array}$ \\
\hline 5 & $\begin{array}{l}\text { Elemen yang satu lebih penting daripada elemen yang } \\
\text { lainnya }\end{array}$ & $\begin{array}{l}\text { Pengalaman dan penilaian sangat kuat menyokong satu } \\
\text { elemen dibandingkan elemen lainnya }\end{array}$ \\
\hline 9 & $\begin{array}{l}\text { Satu elemen jelas lebih mutlak penting daripada } \\
\text { elemen lainnya }\end{array}$ & $\begin{array}{l}\text { Satu elemen yang kuat disokong dan dominan terlihat dalam } \\
\text { praktek }\end{array}$ \\
\hline $2,4,6,8$, & $\begin{array}{l}\text { Satu elemen mutlak lebih penting daripada elemen } \\
\text { lainnya }\end{array}$ & $\begin{array}{l}\text { Bukti yang mendukung elemen yang satu memiliki tingkat } \\
\text { penegasan tertinggi, yang mungkin menguatkan atas elemen } \\
\text { lainnya. }\end{array}$ \\
\hline Kebalikan & $\begin{array}{l}\text { Jika aktivitas } i \text { mendapat satu angka dibandingkan dengan aktivitas } j \text {,maka } j \text { mempunyai nilai kebalikannnya } \\
\text { dibandingan dengan } i .\end{array}$ & Kompromi diperlukan antara dua pertimbangan \\
\hline
\end{tabular}

d. Konsistensi Logis atau Consistency Index (Cl), merupakan indikator konsistensi jawaban atau judgement responden dengan rumus :

$$
\begin{array}{r}
\mathrm{Cl}=(\mathrm{Zmax}-\mathrm{n}) / \\
(\mathrm{n}-1)
\end{array}
$$$$
\text { 1) }
$$

Selanjutnya AHP mengukur seluruh konsistensi penilaian dengan menggunakan Consistency Ratio (CR) dengan rumus :

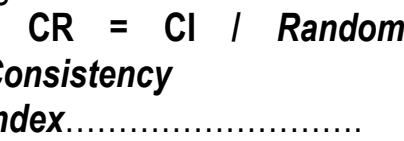

2)

Nilai CR sebaiknya tidak $>10 \%$, jika lebih maka penilaian dilakukan secara random dan perlu diperbaiki.

e. Hasil penilaian dari setiap tahapan yang ditunjukkan oleh nilai bobot atau skala prioritas yang paling tinggi adalah merupakan elemen/faktor yang paling menentukan dalam mencapai tujuan.

Penentuan model konservasi sumber daya air diuraikan ke dalam bentuk hirarki yang terdiri dari : komponen fokus (level 1) adalah kegiatan konservasi sumber daya air, komponen faktor (level 2) yaitu perencanaan, implementasi/ pelaksanaan dan pemantauan dan pengawasan, komponen aktor (level 3) yaitu pemerintah, dunia usaha, masyarakat, LSM/Forum DAS dan perguruan tinggi, komponen tujuan yang ingin dicapai (level 4) yaitu kelestarian sumber daya air, peningkatan pendapatan dan perubahan pola pikir dan komponen terakhir adalah komponen alternatif strategi/kebijakan (level 5) yaitu perlindungan dan pelestarian sumberdaya air, pengawetan air dan pengelolaan kualitas dan pengendalian pencemaran air.

\section{HASIL DAN PEMBAHASAN Keadaan Umum Lokasi}

Berdasarkan metode Isohiet Sub DAS Aek Silang memiliki curah hujan tahunan rata-rata dari tahun $2003-2012$ (10 tahun) adalah sebesar 2.312,09 mm, sedangkan tipe iklim menurut Schmidt Ferguson adalah termasuk Tipe A (sangat basah). Kondisi kemiringan lereng pada umumnya cenderung datar, yaitu $16.314,46$ ha atau $82,34 \%$ dari total luas Sub DAS Aek Silang 19.814,72 ha, hal ini menggambarkan bahwa peluang air terinfiltrasi ke dalam tanah lebih besar. Jenis penutupan lahan didominasi oleh pertanian lahan kering seluas $7.697,56$ ha $(38,85 \%)$ dan hutan tanaman industri 
seluas $6.187,48$ ha $(31,23 \%)$, sedangkan penutupan lahan yang terkecil adalah pemukiman seluas 62,04 ha $(0,31 \%)$. Luas masing-masing penutupan lahan secara terperinci dapat dilihat pada Tabel 3.

Tabel 3.: Jenis Penutupan Lahan di Sub DAS Aek Silang

\begin{tabular}{rrrr}
\hline \multicolumn{1}{l}{ No. } & \multicolumn{1}{c}{ Rincian } & Luas $(\mathrm{Ha})$ & Persentase (\%) \\
\hline 1. & Hutan Lahan Kering Sekunder & $2.538,11$ & 12,81 \\
\hline 2. & Hutan Tanaman Industri & $6.187,48$ & 31,23 \\
\hline 3. & Semak Belukar & $1.919,15$ & 9,68 \\
\hline 4. & Pertanian Lahan Kering & $7.697,56$ & 38,85 \\
\hline 5. & Lahan Terbuka & 357,03 & 1,80 \\
\hline 6. & Pemukiman & 62,04 & 0,31 \\
\hline 7. & Sawah & $1.053,35$ & 5,32 \\
\hline & Jumlah & $19.814,72$ & 100 \\
\hline
\end{tabular}

Sumber : Interpretasi Peta Penutupan Lahan Citra Satelit Tahun 2011

\section{Ketersediaan Air}

Hasil pengukuran stasiun pengamat arus sungai (SPAS) yang dimiliki oleh Balai Sungai Wilayah I Sumatera Utara, menunjukkan bahwa ketersediaan air pada tahun 2003 sampai 2012 adalah berkisar antara 2.219,43 $\mathrm{m}^{3} / \mathrm{det}-4.417,12$ $\mathrm{m}^{3} /$ det, yang secara terperinci dapat dilihat pada Tabel 4.

Tabel 4. Volume Ketersediaan Air di Sub DAS Aek Silang Tahun 2003 - 2012

\begin{tabular}{|c|c|c|c|c|c|c|c|c|c|c|c|c|c|}
\hline \multirow{2}{*}{ Tahun } & \multicolumn{12}{|c|}{ Volume Air (m3/det) } & \multirow{2}{*}{$\begin{array}{c}\text { Jumlah } \\
\text { (m3/det) }\end{array}$} \\
\hline & JAN & FEB & MAR & APR & MEI & JUN & JUL & AGT & SEP & OKT & NOP & DES & \\
\hline 2003 & 349.06 & 285.04 & 261.02 & 255.60 & 231.88 & 274.50 & 133.30 & 420.98 & 378.30 & 633.95 & 642.00 & 551.49 & $4,417.12$ \\
\hline 2004 & 284.30 & 278.50 & 292.00 & 278.00 & 283.80 & 261.70 & 277.30 & 277.00 & 272.60 & 291.30 & 280.80 & 259.16 & $3,336.46$ \\
\hline 2005 & 234.61 & 216.69 & 233.39 & 266.91 & 248.41 & 226.28 & 222.99 & 224.47 & 218.13 & 246.85 & 220.96 & 243.61 & $2,803.30$ \\
\hline 2006 & 477.22 & 411.90 & 428.38 & 378.57 & 360.18 & 318.31 & 304.27 & 271.71 & 229.99 & 216.48 & 198.19 & 212.35 & $3,807.55$ \\
\hline 2007 & 176.70 & 119.00 & 146.32 & 235.20 & 163.06 & 181.80 & 184.45 & 163.06 & 219.30 & 220.10 & 176.70 & 233.74 & $2,219.43$ \\
\hline 2008 & 192.70 & 152.30 & 206.10 & 225.30 & 190.90 & 182.30 & 178.50 & 192.50 & 172.70 & 200.00 & 142.10 & 251.10 & $2,286.50$ \\
\hline 2009 & 474.43 & 410.77 & 529.60 & 566.44 & 281.57 & 156.33 & 108.75 & 159.45 & 270.08 & 164.01 & 232.08 & 349.66 & $3,703.17$ \\
\hline 2010 & 142.06 & 99.61 & 110.05 & 165.88 & 104.62 & 65.82 & 69.26 & 179.86 & 283.82 & 286.95 & 307.22 & 324.40 & $2,139.55$ \\
\hline 2011 & 264.85 & 277.60 & 305.49 & 411.94 & 345.31 & 276.74 & 230.25 & 306.34 & 335.01 & 288.31 & 413.62 & 332.26 & $3,787.72$ \\
\hline 2012 & 310.27 & 330.73 & 271.70 & 402.56 & 345.02 & 303.53 & 333.35 & 349.20 & 320.74 & 390.78 & 391.30 & 253.89 & $4,003.07$ \\
\hline
\end{tabular}

Sumber : Balai Wilayah Sungai I Propinsi Sumatera Utara

Ketersediaan air di Sub DAS Aek Silang apakah mencukupi atau tidak, dapat diperoleh dengan menjumlahkan total pemanfaatan air baik untuk kebutuhan domestik, padi sawah maupun industri listrik. Perincian standard kebutuhan air untuk setiap sektor dapat dilihat pada Tabel 5.

Tabel 5.: Standar Kebutuhan Air

\begin{tabular}{rllc}
\hline No. & \multicolumn{1}{c}{ Sektor } & \multicolumn{1}{c}{ Kebutuhan Air } & \multicolumn{1}{c}{ Keterangan } \\
\hline 1. & Domestik & 60 liter/jiwa/hari $\left(0,06 \mathrm{~m}^{3} / \mathrm{jiwa} / \mathrm{hari}\right)$ & SNI No.:19-6728.1-2002 \\
\hline 2. & Pertanian Padi Sawah & 1 liter/detik/ha $\left(0,001 \mathrm{~m}^{3} /\right.$ detik/ha) & SNI No.:19-6728.1-2002 \\
\hline 3. & Industri Listrik 750 KWh & $6,5 \mathrm{~m}^{3} /$ detik & \\
\hline
\end{tabular}

Berdasarkan Tabel 5. tersebut maka dapat diperoleh total kebutuhan air per tahunnya di Sub DAS Aek Silang, sebagai berikut : 
a. Jumlah penduduk pada tahun 2012, sebanyak 13.924 jiwa, sehingga total kebutuhan air adalah 13.924 jiwa x 0,06 $\mathrm{m}^{3} /$ jiwa/hari $\times 365$ hari adalah $304.935,60 \mathrm{~m}^{3}$ per tahun.

b. Luas padi sawah adalah $1.053,35$ ha dengan lama musim tanam 120 hari per tahun, maka total kebutuhan air adalah $1.053,35$ ha $\times 0,001 \mathrm{~m}^{3} /$ detik/ha $\times 120$ hari adalah sebanyak $10.921 .132,80 \mathrm{~m}^{3}$ per tahun.

c. Kebutuhan air untuk menghasilkan energi listrik sebesar $750 \mathrm{KWh}$ adalah sebanyak $6,5 \mathrm{~m}^{3} /$ detik $\times 86.400$ detik $\mathrm{x}$ 65 hari, yaitu $204.980 .000 \mathrm{~m}^{3}$ per tahun.

Sehingga total kebutuhan air adalah sebanyak 216.210.068,40 $\mathrm{m}^{3}$, sementara volume air yang tersedia pada tahun 2012 menurut Tabel 4. adalah sebanyak $4.003,07 \mathrm{~m}^{3} /$ detik atau $345.865 .248 \mathrm{~m}^{3}$. Dari perhitungan total kebutuhan air dikurangi dengan volume ketersediaan air maka ketersediaan air di Sub DAS Aek Silang masih surplus sebanyak 129.655.179,60 $\mathrm{m}^{3}$.

\section{Strategi / Kebijakan}

Upaya menjaga ketersediaan air agar dapat berkelanjutan adalah melalui kegiatan konservasi sumberdaya air melalui 3 (tiga) kegiatan pokok, yaitu :

a. Perlindungan dan pelestarian sumberdaya air adalah upaya pengamanan sumber daya air dari kerusakan, baik akibat tindakan manusia maupun oleh daya alam, sehingga ketersediaan sumber daya air tetap terjaga sesuai dengan fungsi dan manfaatnya.

b. Pengawetan air adalah upaya pemeliharaan keberadaan (sumber) dan ketersediaan air atau kuantitas air agar tersedia secara berkelanjutan sesuai dengan fungsi dan manfaatnya.

c. Pengelolaan kualitas dan pengendalian pencemaran air adalah upaya mempertahankan dan memulihkan kualitas air yang masuk dan berada di sumber-sumber air sehingga dapat dimanfaatkan.

Strategi konservasi sumberdaya air dengan menggunakan analisis AHP adalah dengan memilih elemen yang mempunyai skor tertinggi dari setiap level dari hirarki yang telah disusun menjadi skala prioritas, dimana hasilnya secara lengkap dapat dilihat pada Gambar 3.

Faktor utama dalam pelaksanaan kegiatan konservasi sumber daya air adalah kegiatan pemantauan dan pengawasan yaitu sebesar $0,390(39,00 \%)$ lebih tinggi dibandingkan dengan faktor perencanaan $\quad 0,296 \quad$ dan implementasi/pelaksanaan $\quad 0,314$. Pemantauan dan pengawasan dilakukan karena sumber-sumber air dan pola pemanfaatan sumber daya air di Sub DAS Aek Silang masih relatif terjaga baik kuantitas maupun kualitasnya.

Level aktor atau pelaku untuk melakukan pemantauan dan pengawasan yang utama dalam rangka kegiatan konservasi SDA adalah Pemerintah $(34,40 \%)$ lebih tinggi dibandingkan dengan kelompok masyarakat $(20,30 \%)$, perguruan tinggi $(17,50 \%)$, LSM/Forum DAS $(15,00 \%)$ dan dunia usaha $(13,90 \%)$. Hal ini menggambarkan bahwa pemerintah memiliki kewenangan untuk mengatur pemanfaatan sumber daya air, melindungi dan melestarikan sumber daya air melalui pembuatan peraturanperaturan dan kebijakan sebagai pedoman dalam rangka melaksanakan kegiatan pemantauan dan pengawasan.

Level tujuan bahwa tujuan utama yang ingin dicapai dari kegiatan konservasi sumber daya air adalah kelestarian sumber daya air $(43,30 \%)$. Hal ini menggambarkan bahwa seluruh kelompok responden terutama kelompok masyarakat, Pemerintah, dunia usaha, LSM dan lembaga pendidikan di wilayah Sub DAS Aek Silang menyadari bahwa manfaat kelestarian sumber daya air sangat penting, agar ketersediaan air 
dapat berkelanjutan. Faktor utama menjaga kelestarian sumber daya air adalah manusia, karena manusia memiliki aktivitas yang dapat merubah penutupan lahan sehingga dapat merubah sistem hidrologi. Disamping itu juga manusia sebagai pihak pengguna atau pemanfaat air sehingga dapat mempengaruhi kuantitas dan kualitas dari sumber daya air.

Level kegiatan alternatif prioritas yang dibutuhkan dalam konservasi sumberdaya air berdasarkan hasil analisis dapat dilihat pada Tabel 6 .

Tabel 6.: Nilai Bobot Prioritas Alternatif Strategi/Kebijakan

\begin{tabular}{rlc}
\hline No. & \multicolumn{1}{c}{ Alternatif Strategi/Kebijakan } & Bobot Prioritas \\
\hline 1. & Perlindungan dan Pelestarian Sumberdaya Air & 0,382 \\
\hline 2. & Pengawetan Air & 0,387 \\
\hline 3. & Pengelolaan Kualitas dan Pengendalian Pencemaran Air & 0,241 \\
\hline & Consitency Ratio (CR) & 0,021 \\
\hline
\end{tabular}

Sumber : Analisis Data Primer, 2014

Berdasarkan Tabel 6 nilai/skor tertinggi dalam kegiatan konservasi sumberdaya air adalah pengawetan air $0,387(38,70 \%)$, sementara perlindungan dan pelestarian sumberdaya air sebesar $0,382(38,20 \%)$ dan pengelolaan kualitas dan pengendalian pencemaran air 0,241 $(24,10 \%)$. Kegiatan pengelolaan kualitas dan pengendalian pencemaran air belum terlalu dibutuhkan karena air di Sungai Aek Silang belum tercemar, dikarenakan sampai saat ini masyarakat masih memanfaatkan air dari Sub DAS Aek Silang untuk kebutuhan sehari-hari.

Sesuai dengan pengertian kegiatan pengawetan air adalah sebagai upaya pemeliharaan sumber-sumber air agar mampu menyediakan air untuk memenuhi keperluan domestik, pertanian dan industri listrik di setiap waktu (sepanjang tahun). Hal ini disebabkan karena air merupakan kebutuhan pokok bagi kelangsungan hidup manusia dan makhluk hidup lainnya sehingga ketersediaan air mutlak dipertahankan.

Ketersediaan air pada sumbersumber air secara terus menerus sangat dibutuhkan untuk memenuhi keperluan domestik, pertanian dan industri listrik. Apabila terjadi kekurangan air, akan mengakibatkan produksi dari usaha pertanian menjadi turun, produksi listrik menjadi terganggu dan kesehatan manusia juga akan menurun. Ketersediaan air yang mulai sulit diperoleh, akan menyebabkan masyarakat akan mengeluarkan biaya tambahan untuk memenuhi kebutuhan air sehari-hari, sehingga menyebabkan pendapatan masyarakat semakin berkurang.

\section{Jenis-jenis Kegiatan Pengawetan Air}

Berdasarkan tujuan pengawetan air adalah suatu upaya untuk menjaga dan melestarikan sumber-sumber air agar ketersediaan air selalu ada dan dapat dimanfaatkan. Beberapa jenis kegiatan yang terkait dengan pengawetan air, yaitu konservasi sipil teknis, rehabilitasi hutan dan lahan (RHL), pengendalian pemanfaatan air melalui pembuatan peraturan, pemeliharaan sumber-sumber air yang masih mampu menyediakan air secara berkelanjutan dan pembinaan/pendampingan bagi masyarakat (Kodoatie dan Roestam, 2010; Purnomo, D.W., dkk., 2015). Jenis kegiatan konservasi sipil teknis adalah upaya untuk mencegah kehilangan air dan mengendalikan erosi, longsor, sedimentasi, banjir dan kekeringan. Adapun jenis kegiatan konservasi sipil teknis yang dibutuhkan di Sub DAS Aek Silang adalah pembuatan dam penahan, pengendali jurang dan terasering. Sementara kegiatan $\mathrm{RHL}$ adalah upaya untuk penanaman pohon- 
pohonan di lokasi lahan yang kritis baik berupa reboisasi pada kawasan hutan dan penghijauan di tanah milik masyarakat. Kegiatan konservasi sipil teknis dan RHL selain untuk menjaga kelestarian sumberdaya air juga dapat menghasilkan sumber-sumber air (Indra, 2013; Rachmat, 2007; Arsyad, 2006).

$$
\text { Kegiatan pengendalian }
$$

pemanfaatan air melalui pembuatan peraturan, pemeliharaan sumber-sumber air yang masih mampu menyediakan air secara berkelanjutan dan pembinaan/pendampingan bagi masyarakat adalah kegiatan pendukung dari pengawetan air.

Pembinaan/pendampingan bagi masyarakat diperlukan untuk meningkatkan partisipasi masyarakat dalam menjaga dan melestarikan sumberdaya air yang ada di Sub DAS Aek Silang. Sesuai dengan Mikkelsen (2011) bahwa dalam kegiatan pembangunan yang berkelanjutan dapat lebih berhasil dengan menggunakan pendekatan partisipatoris masyarakat dengan mengembangkan persepsi, pola sikap dan pola berpikir serta nilai-nilai dan pengetahuan yang dimiliki oleh masyarakat terhadap kondisi sumberdaya air di sekitarnya.

\section{KESIMPULAN}

Ketersediaan air di Sub DAS Aek Silang masih mampu memenuhi kebutuhan air masyarakat (domestik), pertanian dan untuk menghasilkan energi listrik. Ketersediaan air perlu dijaga dan dilestarikan agar pemenuhan kebutuhan air setiap saat dan sepanjang tahun tidak terganggu. Salah satu kegiatan yang dibutuhkan untuk mencapai keberlanjutan air adalah melalui kegiatan konservasi sumberdaya air, yaitu melalui pengawetan air.

Kegiatan pengawetan air berupa pembuatan bangunan sipil teknis, rehabilitasi hutan dan lahan (RHL) berfungsi untuk menjaga kelestarian sumberdaya air juga dapat menambah sumber-sumber air yang baru, sementara kegiatan pengendalian pemanfaatan air, pemeliharaan sumber-sumber air dan pembinaan/pendampingan untuk meningkatkan partisipasi masyarakat adalah kegiatan pendukung bagi pengawetan air.

\section{DAFTAR PUSTAKA}

Arsyad, S., 2006, Konservasi Tanah dan Air, IPB Press, Bogor.

Asdak, C., 2010. Hidrologi dan Pengelolaan DAS, Gadjah Mada University Press, Yogyakarta.

Asner,G.P., Loarie,S.R., Heyder,U., 2010, Combined Effects of Climate and Land-use Change on the Future of Humid Tropical Forests, Conservation Letters, 3: 395 - 403.

Ethika, D., Purwanto, R.H., Senawi, Masyhuri, 2014, Peranan Petani Terhadap Strategi Pembangunan Hutan Rakyat di Bagain Hulu Sub DAS Logawa di Kabupaten Banyumas, Jawa Tengah, Jurnal Manusia dan Lingkungan, Vol.21 No. $3: 377-385$.

Gilbert, G., 2005, World Population A Reference Handbook Second Edition, ABC-Clio Inc, California.

Igbawua,T., Zhang,J., Chang,Q., Yao,F., 2016, Vegetation Dynamics in Relation with Climate Over Nigeria from 1982 to 2011, Environment Earth Science, 75:518.

Indra,T.L., 2013, Dampak Penggunaan Lahan Terhadap Tingkat Kekritisan Air Sub DAS Citarum Hulu, Majalah Geografi Indonesia, Vo. 27 No.1: 26 -37 .

Irawan,D.E., Silaen,H., Sumintadireja,P., Lubis,R.F., $\quad$ Brahmantyo,B., Puradimaja,D.J., 2014, GroundwaterSurface Water Interaction of Ciliwung River Stream, Segment Bogor- 
Jakarta, Indonesia, Environmental Earth Science, 73 : 1295 - 1302.

Kim, G.B., Ahn, J.S., Marui, A., 2009, Analytic Hierarchy Models for Regional Groundwater Monitoring Well Allocation in Southeast Asian Countries and South Korea, Environmental Earth Science, 59 : $325-338$.

Kodoatie, R.J. dan Roestam, S., 2010, Pengelolaan Sumber Daya Air Terpadu, Penerbit Andi, Yogyakarta.

Liu, Y., 2005, Land Use/Cover Changes, the Environment and Water Resources in Northeast China, Environmental Management Vol.36 No.5: 691-701.

Liu, Y. and Yaning, C., 2006, Impact of Population Growth and Land-use Change on Water Resources and Ecosystems of the Arid Tarim River Basin in Western China, International Journal of Sustainable Development and World Ecology Vol.13: 295-305.

Loebis, J., 1999, Hidrologi Danau Toba dan Sungai Asahan, PT.Puri Fadjar Mandiri, Jakarta.

Marganingrum, D., 2007, Kondisi Citarum Saat Ini dan Strategi Pengendaliannya dalam Sumber Daya Air dan Lingkungan Potensi, Degradasi dan Masa Depan, Diedit oleh Delinom, R.M., Dyah M, Jakarta : LIPI Press, hal.21.

Mikkelsen, B., 2011, Metode Penelitian Partisipatoris dan Upaya Pemberdayaan, Yayasan Pustaka Obor Indonesia, Jakarta.

Muta'ali, L., 2012. Environmental Carrying Capacity Based on Spatial Planning, Indonesian Journal of Geography, Vo.43.(2) : 142 - 155.

Ongkosongo, O.S.R., 2010. Kuala, Muara Sungai dan Delta, Penerbit LIPI, Jakarta.

Park, J.H., 2010, A Study on the Comparative Method Using AHP and
GIS Based Distributed Model Runoff Model, KSCE Journal of Civil Engineering, Vol. 14, No. 6 : 953-960. Purnomo,D.W., $\quad$ Sandrawati,A., Witono,J.R., $\quad$ Fijridiyanto,I.A., Setiyanti,D., Safarinanugraha,D., 2016, Desain Vegetasi Bernilai Konservasi dan Ekonomi Pada Kawasan Penyangga Sistem Tata Air DAS Bolango, Jurnal Manusia dan Lingkungan, Vol.23 No.1 : 111-121

Rachmat, A., 2007, Dampak Perubahan Tata Guna Lahan Terhadap Ketersediaan Air Tanah di DAS Citanduy Berdasarkan Koefisien Infiltrasi dalam Sumber Daya Air dan Lingkungan Potensi, Degradasi dan Masa Depan, Diedit oleh Delinom, R.M., Dyah M, Jakarta : LIPI Press, hal.21.

Saaty, T.L., 2008, Decision Making With the Analytical Hierarchy Process, Int. J. Services Sciences, Vol.1,No.1 : 8398, 2008 <www.fcmfmpep.org.br/ disciplinas/MB-

721/.../Artigo_Saaty_2008.pdf > (Diakses 19 Februari 2013).

Sihite, J., 2005, Penilaian Ekonomi Perubahan Penggunaan Lahan : Studi Kasus di Sub DAS Besai-DAS Tulang Bawang Lampung, $<$ http://repository.

ipb.ac.id/bitstream/handle/123456789 /340/2004jhs.pdf?sequence=4> (Diakses 9 November 2011).

Sudarmadji, Slamet, S. dan Setiadi, 2012, Konservasi Mata Air Berbasis Masyarakat di Kabupaten Gunung Kidul, Sekolah Pasca Sarjana Universitas Gadjah Mada, Yogyakarta.

Zeppel,M.J.B., Wilks,J.V., Lewis,J.D., 2014, Impacts of Extreme Precipitation and Seasonal Change In Precipitation on Plants, Biogeosiciences, Vol.11 : 3083-3093. 